\title{
The effect of teaching without pedagogical training in St. Paul's Hospital Millennium Medical College, Addis Ababa, Ethiopia
}

This article was published in the following Dove Press journal: Advances in Medical Education and Practice

\section{Teshale Biku' \\ Tangute Demas ${ }^{2}$ \\ Negat Woldehawariat ${ }^{1}$ \\ Meaza Getahun ${ }^{2}$ \\ Altayework Mekonnen² \\ 'Operating Theater Nursing Education Department, St. Paul's Hospital Millennium Medical College, Addis Ababa, Ethiopia; ${ }^{2}$ Surgical Nursing Education Department, St. Paul's Hospital Millennium Medical College, Addis Ababa, Ethiopia}

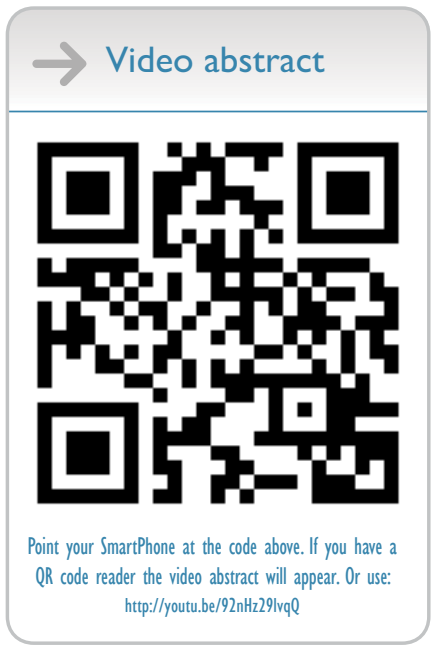

Correspondence: Teshale Biku Operating Theater Nursing Education Department, St. Paul Hospital Millennium Medical College, PO Box I27I, Addis Ababa, Ethiopia

Email teshalebiku@yahoo.com
Background: The recent expansion of higher education institutions in Ethiopia provides an opportunity for many citizens who did not previously have access to higher or university level education. This opportunity, however, comes with its own challenges, such as ensuring that minimum standards are set and maintaining quality where pedagogical concerns are compromised. The aim of this study is to explore the effect of teaching without pedagogical training, in St. Paul's Hospital Millennium Medical College (SPHMMC), Addis Ababa, Ethiopia.

Methods: An institutional-based qualitative phenomenological study was conducted through an in-depth interview, using purposive sampling techniques. Participants were instructors and students selected from SPHMMC who had participated in the teaching or learning process or at least 24 months. Owing to data saturation, only 16 instructors and seven students were interviewed, using open-ended and semi-structured questions. Tape recorders and field notes were used. Based on thematic aggregation, the content of the responses was analyzed.

Results: Only one of the 16 instructors had received pedagogical training for more than one year. Twelve instructors had received 2 days to 2 weeks of training, and the rest were using a personal method of teaching. During the recruitment procedure, only one instructor had been asked to verify their pedagogical background. However, all respondents confirmed that pedagogical training is very important to facilitate the teaching-learning process. In this study, most of the instructors practiced their personal teaching methods, which resulted in no common delivery system of teaching content, which can be huge, no lesson plan, no clear objectives to courses, poor time management, different instructors having overlapping course content, no table of specifications, and no proper evaluation mechanisms for either the students' or the teachers' performance. On the students' side, because of the vast and unplanned course content and poor time management, their participation in the learning process was insufficient, which could affect their learning.

Conclusion: Because of the gap in pedagogical training, college teachers use personal teaching methods, and this negatively affects the standardization of delivery methods. To improve this drawback, proper pedagogical training should be provided for all teachers. This would help them to deliver quality education and to produce competent graduates from the institute to supply the workforce.

Keywords: evaluation, instructor, perception, pedagogy, St. Paul's Hospital Millennium Medical College, teaching without training

\section{Introduction}

Education is one of the major public investments in building the capacity of human resources with a multidimensional aim, including economic, cultural, and social benefits. Thus, it needs proper attention to provide quality input to stakeholders. However, 
it has been observed that quality is being compromised. The quality of education is greatly affected by the lack of sufficient qualified teachers and facilities such as space, reference materials, and teaching aids or models. Inadequate systems for evaluating students and the lack of training for most instructors can also make teaching impractical. ${ }^{1}$

Quality teaching is highly correlated with the use of effective pedagogical techniques to bring learning to students. It involves several dimensions, such as designing an effective curriculum and course content, the use of a variety of learning contexts (guided independent study, project-based learning, collaborative learning, experimentation, etc), soliciting and using feedback, and effective assessment of learning outcomes. It also involves well-adapted learning environments and student support services. ${ }^{2}$

Even though the quality of teaching in higher education has an impact on students' learning outcomes, it is confronted with various challenges from different directions. Gaps are often found between the expectations of students and the readiness of instructors to provide appropriate lessons in the education sector. Instructors are highly expected to engage in designing curricula, conducting assessments, and delivering conventional classes in their teaching through integrating new technologies. ${ }^{2,3}$ However, several studies around the world have shown that this is not always the case.

A study conducted in Japan revealed that most of the teachers were not fully competent and, as a result, national advisory groups made the improvement of teacher training the main theme for educational reform. ${ }^{4}$ Another study conducted in Slovenian higher education, on teaching and the pedagogical training of university teaching staff, revealed that only $31.4 \%$ of all respondents had participated in higher education pedagogical training. ${ }^{5}$

A study carried out in Makerere University, Uganda, to address the pedagogical training needs of teaching staff showed that teachers needed training regarding the assessment and grading of students, managing large classes, and using information and communications technology (ICT) in teaching and learning. ${ }^{6}$

According to a study in Kenyan universities, there was a shortage of lecturers and this reduced the effectiveness of lecturers in presenting good-quality lessons in their classes. To cope with a shortage of lecturers and to minimize staff workload, there is a tendency to employ incompetent staff for teaching. ${ }^{7}$

In Ethiopia, the main pedagogical strategy used by instructors is the lecturing method. Although some of the participants in the study knew the theoretical underpinnings of engaging strategies, they did not implement such engagement in their day-to-day lessons. Even fewer teachers understood the importance of educational relevance or knew how to make small changes to provide more relevant instruction. ${ }^{8}$

It is very difficult to provide access to quality education without properly managing factors related to teacher training and professional development, such as the provision of well-run pre-service and in-service training, plus continuous professional development focusing on content knowledge, pedagogy, and language skills. ${ }^{9}$

Studies on the proportion of instructors receiving pedagogical training and its effect on their teaching experience, particularly in the field of health sciences, are scarce in Ethiopia. Effective teaching skills are very important for teaching staff and are emphasized in the preparation of teachers, adult learning principles, and the use of modern technology in an educational environment. ${ }^{10,11}$

The absence of pedagogical training of university instructors often results in the maintenance of the old methods of teaching, which often focus on the instructors instead of the needs of students and on the subject matter instead of the transfer of knowledge. ${ }^{12}$

A good teaching method helps students to question their preconceptions and motivates them to learn, by putting them in a situation in which they come to see themselves as the authors of the answers and the agents of responsibility for change. ${ }^{13}$

In the traditional system, instructions are teacher centered, and the students' needs and interests are not considered. Therefore, instruction must be changed toward a method in which the needs of students are considered, so that active behavioral change can occur. ${ }^{14}$ Research and exploration to determine useful and effective teaching and learning methods are one of the most important requirements of any educational system. ${ }^{15}$

Offering effective teaching and producing good-quality graduates requires university instructors to possess a combination of knowledge of the subject matter and pedagogical skills; however, in Ethiopia, university instructors are recruited on the strength of their class of degree rather than pedagogical knowledge and skills. Most of the instructors who are engaged in higher education have not been trained in teaching methodologies. As a result, they lack confidence since they are not given further training opportunities, books, and similar teaching aids to participate fully in the scenario. ${ }^{16}$

The purpose of this study is to assess the effect of teaching without pedagogical training in teaching staff at St. Paul's Hospital Millennium Medical College (SPHMMC), Addis Ababa, Ethiopia. 
Hence, this study will attempt to answer the following questions:

1. What is the pedagogical background of teachers in SPHMMC?

2. What is the current teaching approach in SPHMMC?

3. What are teachers' perceptions of teaching without pedagogical training?

4. How do students perceive the teaching approach?

5. What is the effect of teaching without pedagogical training?

\section{Methods}

\section{Study area and period}

The study was conducted at SPHMMC, in Addis Ababa, Ethiopia. SPHMMC is one of the largest public hospitals in the country, providing academic, research, and medical services. The college provides BSc and MSc degrees, training for public health and nursing in different areas as well as in medicine, as a first degree and as specialties in many clinical fields (eg, surgery, radiology). The study was conducted from April to June 2017.

\section{Study design}

An institution-based, qualitative phenomenological study design was used to assess the effect of teaching without pedagogical training.

\section{Study population}

The study population comprised medical doctors (eg, gynecologist, surgeon, anesthesiologist; ear, nose, and throat doctor; gastrointestinal doctor), college lecturers, and students from different levels (residents, interns, and specialty nursing students) of SPHMMC.

\section{Sample size and sampling technique}

All respondents (teachers and students) were purposefully selected by considering their years of experience, as those with more experience would be expected to answer questions on the teaching-learning process more fully. To start with, 20 teachers and ten students with at least 2 years of teaching and learning experience were selected. However, owing to data saturation we used only 16 teachers and seven students. In total, 23 participants were interviewed before the data became saturated.

\section{Data collection instruments and techniques}

The interview guiding questions were prepared based on previous literature ${ }^{17,18}$ and modified for our context. Detailed discussion was undertaken by a group of experts (lecturers and medical doctors) to relate the interview questions to the local context and make them easily understandable by the respondents. The interview guide questions were pretested in a similar setting, at Menelik Hospital Health Science College, Ethiopia, to give the data collectors some practical exposure and to obtain feedback on improving the interview guide.

Two trained lecturers, data collectors, and one supervisor were recruited for data collection. Training regarding the objective of the study and ways of probing the information was given to the data collectors and supervisor before the actual data collection. The interview was moderated by the principal investigator, collaborators, and trained data collectors. A tape recorder and notebook were used during data collection.

\section{Data quality assurance}

The quality of data was assured through careful adaptation and pretesting of the interview guide questions, proper training of the data collectors and supervisors, and close supervision of the data collection procedure. Proper categorization and coding of the data were followed attentively. The collected data were checked for completeness daily.

\section{Data analysis}

Tape-recorded data were transcribed and extensive notes of interviews were reviewed. The information was transcribed based on the thematic aggregation. Thematic analysis was applied by line-by-line reading of the verbatim transcript. Prominent themes were categorized into subthemes. Verbatim answers were frequently used to illustrate the responses of respondents to important issues and subthemes. It should be noted that the answers quoted in the Results section of this article have been lightly edited for clarity in English. Frequencies of occurrence (sociodemographic characteristics and pedagogical training) were also assessed.

\section{Ethical approval and consent of participants}

Ethical approval and clearance were obtained from the SPHMMC Institutional Review Board. There was no potential risk that might cause any harm in any form to the study subjects. After permission had been obtained from the Review Board, participants were provided with information about the objectives and importance of the study. Informed written consent was obtained in advance from the study subjects. All information that was communicated with individual subjects or organizations was kept private and confidential. 


\section{Results}

At the beginning, 20 lecturers (from clinical and basic science departments) and ten students from different departments were selected purposefully to participate in the study. Later, 16 lecturers and seven students were asked to respond to semi-structured in-depth interview questions. Most of the respondents had received days or weeks of pedagogical training. One had received 2 months of training and only one respondent had had pedagogical training for more than a year. Two lecturers from the selected participants and one selected student refused to join the interview and the rest were left out because of data saturation. The sociodemographic profile of study respondents is shown in Table 1.

\section{Research question I:What is the pedagogical background of teachers in SPHMMC?}

Out of 16 respondents, 12 said that they had received days or weeks of training on issues related to pedagogy. One of them had had 2 months of training in his higher diploma program. Only one of the respondents had received pedagogical training for more than a year at an undergraduate level. Three respondents did not have any pedagogical training (Figure 1). Most of them had more than 6 years' work experience. Thus, most of the teachers are teaching without having undergone proper pedagogical training.

In relation to this, respondents were asked about the teaching staff recruitment procedures of the college. Only one had been asked to verify their pedagogical background.

I was assigned to the clinical area, but I changed my engagement to teach. For example, in my department, when we interview potential candidates, we focus on their answers to questions. There is no pedagogy-related question. The college needs to provide the pedagogical training afterward. [interview 205: DN].

In the hiring process, there was an interview, a presentation on a certain topic, and a document check-up. More-

Table I Study participants' sociodemographic characteristics

\begin{tabular}{|c|c|c|c|c|c|c|c|}
\hline Participant ID & $\begin{array}{l}\text { Lecturer } \\
\text { type }\end{array}$ & $\begin{array}{l}\text { Age } \\
\text { (years) }\end{array}$ & Gender & $\begin{array}{l}\text { Highest degree } \\
\text { earned }\end{array}$ & $\begin{array}{l}\text { Years in } \\
\text { practice }\end{array}$ & $\begin{array}{l}\text { Time taken } \\
\text { for interview } \\
\text { (minutes) }\end{array}$ & $\begin{array}{l}\text { Pedagogical } \\
\text { training } \\
\text { received }\end{array}$ \\
\hline \multicolumn{8}{|l|}{ Lecturers } \\
\hline 200 & BS & 32 & Female & Master's & 4 & 35 & None \\
\hline 201 & GY & 38 & Male & Doctorate & 12 & 36 & 2 weeks \\
\hline 202 & AN & 53 & Male & Doctorate & 25 & 21 & 2 days \\
\hline 203 & NE & 28 & Male & Master's & 7 & 45 & I month \\
\hline 204 & SW & 25 & Female & Master's & 2.5 & 35 & 2 weeks \\
\hline 205 & $\mathrm{DN}$ & 29 & Female & Doctorate & 2 & 35 & 2 days \\
\hline 206 & EM & 35 & Male & Master's & 2 & 35 & I week \\
\hline 207 & PD & 29 & Female & Master's & 7 & 30 & 3 days \\
\hline 208 & $\mathrm{BS}$ & 31 & Female & Master's & 2 & 40 & I week \\
\hline 209 & PD & 28 & Female & Master's & 4 & 35 & 2 months \\
\hline 210 & BS & 32 & Male & Master's & 12 & 49 & 2 years \\
\hline 211 & BS & 38 & Male & Master's & 12 & 40 & None \\
\hline 212 & EN & 60 & Male & Doctorate & 23 & 46 & None \\
\hline 213 & SU & 40 & Male & Doctorate & 10 & 50 & 2 weeks \\
\hline 214 & IN & 45 & Male & Doctorate & 10 & 34 & 2 weeks \\
\hline 215 & OP & 54 & Female & Doctorate & 28 & 45 & 2 days \\
\hline \multicolumn{8}{|l|}{ Students } \\
\hline 400 & OR & 26 & Male & OR nurse student & 0 & 35 & 0 \\
\hline 401 & OR & 24 & Male & OR nurse & 0 & 25 & 0 \\
\hline 402 & ER & 25 & Female & Emergency nurse & 0 & 25 & 0 \\
\hline 403 & ME & 28 & Female & $\begin{array}{l}\text { Orthopedic } \\
\text { resident }\end{array}$ & 2 & 21 & 0 \\
\hline 404 & ME & 29 & Female & $\begin{array}{l}\text { Third year } \\
\text { medical student }\end{array}$ & 0 & 20 & 0 \\
\hline 405 & ME & 25 & Female & $\begin{array}{l}\text { Third year } \\
\text { emergency nurse }\end{array}$ & 0 & 20 & 0 \\
\hline 406 & ME & 23 & Female & $\begin{array}{l}\text { Fifth year intern } \\
\text { student }\end{array}$ & 0 & 18 & 0 \\
\hline
\end{tabular}

Abbreviations: AN, anesthesiologist; BS, basic science; DN, dentist; EM, emergency doctor; EN, ear, nose, and throat doctor; ER, emergency room student; GY, gynecologist; IN, internist; ME, medical student; NE, neonatal doctor; OP, ophthalmologist; OR, operating room nurse student; PD, pediatric doctor; SU, surgeon; SW, surgical ward doctor. 


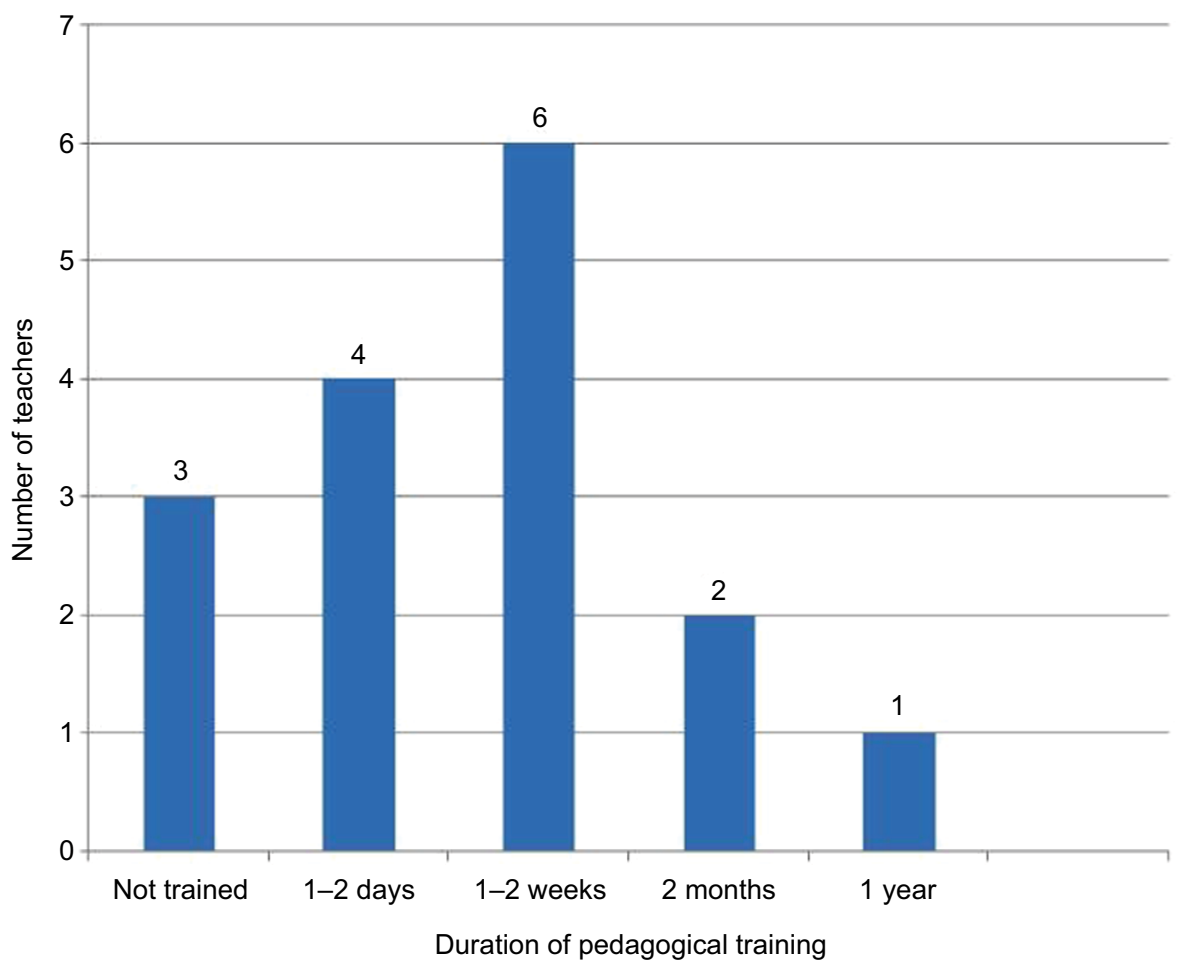

Figure I Pedagogical training levels of respondents in St. Paul's Hospital Millennium Medical College, May 2017.

over, all these were focused on clinical aspects and content elements.

\section{The value of teaching and pedagogical training for teachers}

The teaching staff of SPHMMC is recruited from among the hospital staff, who have had no prior pedagogical training. Some of them are fresh graduates and others have teaching experience in the health sector. However, their perception of the value of pedagogical training was positive. All respondents confirmed that pedagogical training is very important to facilitate the teaching-learning process.

If teachers don't have pedagogical training, they are unable to set their lesson objective, so then they become disorganized. Having pedagogical training is helpful in many ways. For one thing, it helps them to set their objective in a concrete way. In addition, they make their class participatory, and set up the class for group discussion. [interview 208: BS].

In addition:

Pedagogy is very necessary to centralize the teachinglearning process. It helps to have a proper delivery system and similar evaluation mechanism, and it helps the teacher to follow up activities in a scientific way. There should be continuous evaluation in the way that teachers are monitored since they do not have equal attitudes toward teaching. [interview 211: BS].

Thus, if teachers give a lesson without taking pedagogical training, they can face challenges in the effective delivery of courses. They may find it difficult to manage their classes as well as their time.

\section{Research question 2: What is the current teaching approach in SPHMMC?}

Respondents were asked about their current teaching methods at SPHMMC. All reflected that teachers have their own techniques to make the teaching-learning process effective. Their teaching approaches are categorized as focusing on "lecture methods" and "participatory" approaches.

As mentioned by a respondent from basic science:

To make my teaching effective, I regularly use a lecture method. Then I move on to discussion. Since my course, Anatomy, has practical components, a small number of students attend during practice. This helps to demonstrate and discuss issues in my class. [interview 212: EN].

Some respondents mentioned teaching a large number of students and inadequate time being allocated for a given course as challenges. They also highlighted the lack of opportunities to improve their teaching skills so that they 
could handle the challenges they face. They were dependent on hard copies, computers, and projectors.

I lecture in my class to cover vast course contents which are difficult to apply active learning to. Because of this, PowerPoint slides are presented many at a time, which students lack concentration to follow [...]. [interview 209: PD].

I usually lecture my students. I use my life experience in teaching. Of course, it's difficult to say I have enough ways of teaching. There are some problems. The space is crowded. There is a lack of proper training to upgrade ourselves in spite of the fact that there is some continuous education in the medical area. We miss this because of our workload. [interview 204: SW].

\section{Theoretical and practical assessment mechanisms}

When asked about the balance between practical and theoretical aspects, 13 of the respondents said that they evaluate their students in both aspects.

Concerning the assessment coverage, almost all of the respondents said that they prepared questions from the course content covered in relation to the time allocated to units and sections. Most of the respondents, however, focused on the cognitive domain, and they did not use a table of specifications.

Regarding the students' feedback about the way they were assessed, many of the respondents said that students are grade oriented so that they give feedback accordingly. For instance:

Students do not give us proper feedback about the exam.

They focus on their grade. If they have good scores, they think that the exam is good. Many respondents usually say that the exams are difficult to answer. The reality, however, is they are weak. They are far from acquiring standard or facilitated because their selection was by a quota system [giving a chance for students from emerging regions to join the college with low grades]. [interview 203: NE].

Almost all 16 respondents said that in their written exam, they started by setting multiple choice questions (MCQs), true/false questions, short-answer questions, and essays, as they wished, rather than setting questions from easy to hard. However, some of the respondents said that they did not prepare essay questions because of the number of students in a class.

When I prepare an exam, first I consider the homogeneous and heterogeneous nature of my questions. In this campus, the nature of exams is inclined to be heterogeneous and items are focused on MCQs and short answers. Because of the number of students, teachers do not have an appetite to prepare essay questions, for fear that marking is challenging and time consuming. I use the college grading standard, which is the fixed scale. [interview 208: BS].

\section{Accessibility of teaching materials and classrooms}

Thirteen respondents said that they had concerns over the scarcity of space for demonstrations. For example, a clinical level student said that, in a demonstration room or skill lab:

Materials like teaching aids and laboratory are not accessible $[. .$.$] there is no manual checklist; as a result, teachers'$ evaluation becomes more subjective. Different teachers may evaluate students for the same task in different ways that affect quality directly. [interview 203: NE].

Thus, the problems of not having enough space to teach a large number of students, and a shortage of classrooms, demonstration rooms, and simulation opportunities, are challenges competing with quality in the current situation.

\section{Research question 3:What are teachers' perceptions of teaching without pedagogical training?}

The respondents liked teaching as a profession and were interested in receiving pedagogical training. However, when they were asked about other teachers' interest in training, they reported that some teachers do not have the determination for self-improvement.

Honestly speaking, some teachers do not have the initiative to improve themselves. They don't accept the profession as their work and are not interested in teaching. They are careless and negligent with regard to content. There should be a change in the teaching mentality. We have to show them the benefits. [interview 207: PD].

Another respondent from the clinical side said:

Few are committed, but many of the teachers are not ready to improve themselves. They are not ready to listen to others. It is somewhat frustrating. To improve the challenges, as an individual, I try my best. The college, however, should pay attention. For instance, instead of having 100 students, focusing on quantity, it's worth teaching 10-20 students, focusing on quality. [interview 215: OP]. 


\section{Effects of pedagogical training on teaching}

Teachers have different perceptions of teaching when it comes to carrying on their profession with pedagogical training or without it. In light of this, respondents were asked how they perceived their pedagogical skills and what factors would be considered for improvement of their pedagogical skills.

Twelve of them had improved their teaching skills and were satisfied with their teaching because of the training. They mentioned that they do not focus on just a few points and care about their students and the content. Moreover, they concluded that teaching without pedagogical training is incomplete. They also emphasized that pedagogical training helped them to "think how to think". It guides them in how to teach and how to manage classes.

In addition:

Pedagogy is very necessary to centralize the teachinglearning process. It helps to have a proper delivery system and similar evaluation mechanism. It helps teachers to follow up activities in a scientific way. [interview 403: ME].

The rest of the respondents were using traditional or personal methods of teaching without much confidence and were giving out bulky handouts that students could not manage to read within the given period of time. Thus, if teachers teach without undertaking pedagogical training, they can face great challenges that will create problems in quality. They believed that their teaching lacked organization, they were unable to present their lessons well, and they could not manage their classes or their time; as a result, their evaluation mechanisms became a challenge.

Lecturers need to be skillful in creating conditions for better learning. Teaching experience and personal interest help teachers to improve their teaching. A teacher from the clinical side reflected:

Concerning my teaching style, I don't say I am perfect, but, I use my way [...] if I feel that new method is good, I try to apply [...] well, I get my style from my teaching experience and I improve it from year to year. In addition, feedback from my students is very helpful. I regularly (not at the end of the course) take feedback. I listen to my students, then, I put their suggestions into practice. Since I am module coordinator, I get a chance to discuss with my students not only about my course, but also about other teachers' courses. [interview 406: ME].

Thus, some teachers are interested in their teaching. They have brought their experience in teaching and agree that pedagogical training has a great effect on the quality of education.

\section{Evaluation and promotion schemes and teachers' performance}

Teaching without receiving pedagogical training has a negative impact on the teaching-learning process. Respondents were asked whether there are evaluation systems regarding teachers' performance in the college. All respondents except one said that there were no evaluation mechanisms.

There is a teachers' performance evaluation format, but I haven't seen it being used. There are no evaluation mechanisms used by the college. I used to evaluate my students, beyond the course, by their discipline to the class, their personality as a student. Otherwise, my evaluation is related to exams. [interview 206: EM].

There is a system or an attempt in the college to evaluate teachers. There are also relevant bodies at both department and college level; however, they are not effective in implementing such evaluation.

\section{Research question 4: How do students perceive the teaching approach?}

Students were asked how they perceived the teachinglearning process in the college. Five of the respondents said that although there were good sides to the teaching-learning process, there were also negative aspects, especially relating to teachers.

I have been here for the last two years. It seems there is a system, but it is full of problems. The first-year program was fine. Teachers were well organized, and they respected their students. This year we are facing many hurdles. There is a shortage of teachers. Even those who are teaching miss many classes, and they also disturb the schedule and it affects us. Some teachers are not related to our department and this leads us to learn irrelevant content. The course contents are fragmented and assigned to be covered by different teachers. As a result, students lack concentration. [interview 404: ME].

The number of students affects the teaching-learning process, in that teachers are forced to focus on only lectures. In the first and second years, the whole process is dependent on the teachers. In the third and fourth years, however, the method comprises bedside teaching and demands a lot of reading. It also relies on which patients the students follow as their attachment. 
Thus, it is known that teachers are deficient in time management because they miss classes for various reasons. The number of students also affects the time spent teaching.

Students believed that pedagogy would make teachers better in the teaching-learning process, although they did not know what it meant. However, it was difficult to identify teachers who had received pedagogical training. They all believed that teachers who were ready to teach and allowed student participation may have obtained value from training.

[...] The quality of education is measured based on the output. If students gain knowledge, there is quality. Teachers, instead of simply lecturing, should check their students' understanding in some way or another. [interview 401: OR].

This reflects that although students did not comment on their teachers' pedagogical training, they did have opinions on the actual class performance and expected outcomes.

\section{Students' perception of evaluation}

Students were expected to know the evaluation system of the college. Many of the respondents, however, had not discussed this with their teachers or the concerned body, and they did not know about the college's evaluation system. A clinical level III student said:

We always make ourselves ready during clinical evaluation, but the patient sometimes matters. Teachers [assessors] affect us since it becomes more personal. [interview 403: ME].

Some teachers focused on only a few units and some prepared exams on topics that students had not learnt, without a table of specifications. Thus, although they had discussions with teachers or officials, they seldom obtained a positive response. The evaluation system, however, varied from teacher to teacher.

In the clinic, there are four or five supervisors. They give similar marks for those who work and who don't work because of their negligence to follow students. The evaluation method is OK. However, it demands memorization rather than internalizing concepts. Memorization is over and done within the exams. It would be better if it was about understanding the principles. I don't know about a table of specifications, but there can be a match between the content and lecture hours when the exam is prepared. We have $60 \%$ value for mid 1 and mid 2 . The other $40 \%$ is new information from the materials. In addition, what we present for one assessor and what he grades may entirely vary when we present the same topic to another one. [interview 405: ER].
Pertaining to the evaluation of teacher performance, many of the students did not know about this. They believed that if there was evaluation, it would help teachers to take feedback and apply corrective measures to their preparation. Finally, students pointed out that teachers should be qualified and skilled. This will help them to interact with their students and add value to their classes.

Students' responses about the evaluation system varied as a result of their perspectives. Some are adults and have a certificate or diploma, whereas others join through the entrance exam directly from high school. Still others are students in their specialization.

[...] Regarding teachers' lesson delivery system and students' response, I don't have the full information. However, students complain about teachers breaking the timetable. After they miss a class, they force students to set another timetable, which potentially disturbs their program. Some teachers' voices are not audible to the students. Others use old slides or presentations in their class. [interview 200: BS].

\section{Students' participation in teaching}

Students had different views on their feedback and attitude toward improving the learning process in the college. Eleven respondents had a positive attitude toward the students' situation in their respective class, while seven of the respondents had a negative attitude. The students pointed out that their involvement in providing feedback and reflecting their attitude had an impact on the teaching-learning process. For example, as a clinical level respondent pointed out:

\section{[...] Teachers should take regular feedback from their students to be effective in the teaching-learning process. [However,] students do have a chance to give feedback about the teaching-learning process. Teachers are weak in their teaching and they do not prepare for class. If they take the training, they will be effective. The first thing that should give due attention to bring quality of education is when someone is recruited to be a teacher. [interview 402: ER].}

Students are also aware of the effect of the number of students in a class, which greatly affects their understanding. In most higher institutions, lectures are used to teach larger classes.

\section{Challenges of the teaching-learning process}

Different challenges affect quality in the current teaching approach. The students' selection criteria, the teaching envi- 
ronment, and teaching without training are the three main pillars that affect quality. In addition, the development of the curriculum lacks a clear design with regard to content and objectives.

First, the students' selection criteria and quota system are challenges. There were many students in a class, and some students were less interested owing to the quota system. According to a respondent from the clinical level:

\section{[...]. There is a mismatch between the number of students} and space in the college. In the hospital, patients are stressed because of the large number of students present at one time. [interview 200: BS]

In addition, a basic science respondent said that:

[...] the number of students becomes challenging to manage and evaluate effectively. [interview 204: SW].

Second, a shortage of classrooms, skill labs, laboratories, and clinical settings to accommodate the large number of students was another challenge in the college which compromised the quality of the teaching-learning process.

To provide proper teaching (demonstration, clinical attachment), the number of patients is limited in relation to the number of students. It's difficult to have practice and even to monitor students, and this affects students' skills. [interview 204: SW].

Thus, in one way or another, the respondents claimed that there is a shortage of space. It is a shame to have to talk about quality without having the rooms, laboratories, and available materials for demonstration in SPHMMC.

Third, the curriculum and teachers' training have been mentioned as challenges to dealing with quality. The content of some courses needs revision as it is too bulky to manage.

The number of students, not including teachers in the reforms, and there being an overload in the health sector [hospital service] can be factors that affect quality. For example, in the case of the number of students, I am forced to take the first and second batch students together for the same patient. [interview 200: BS].

\section{Research question 5: What is the effect of teaching without pedagogical training?}

Teachers were dependent on prepared notes, hard copies, computers, and projectors. In addition, because of a lack of pedagogical training they usually used lecture methods, and this affected the effectiveness of the teaching-learning process to transfer enough knowledge and skills.

I lecture in my class to cover the vast course content, which it is difficult to apply active learning to. Because of this, PowerPoint slides are presented many at a time, which students lack concentration [...]. [interview 209: PD].

I use my life experience in teaching. Of course, it's difficult to say that I have enough ways of teaching. [interview 204: SW].

Most of the college teachers did not provide the students with the objectives or syllabus of the course. They used bulky course contents without a proper lesson plan, owing to their lack of pedagogical training. This affected the teachinglearning process greatly.

If teachers don't have pedagogical training, they are unable to set their lesson objective, so they become disorganized. Having pedagogical training is helpful in many ways. For one thing, it helps them to set their objective in a concrete way. In addition, they make their class participatory and set up the class for group discussion. [interview 203: NE].

The evaluation system, varied from teacher to teacher and negatively affected the students' evaluation outcome.

It would be better if it was about understanding the principles. I don't know about a table of specifications. But it can be a match between the content and lecture hours when the exam is prepared. [interview 405: ER].

All respondents reflected that quality education is expected through teachers' pedagogical readiness, students' active participation, and the availability of sufficient materials to help students to acquire the knowledge to the standards laid down. Lack of these resources highly affects the teachers' confidence to teach and directly reflects on the students' levels of general knowledge and skill.

To give quality education, there should be enough fieldspecific teachers in the department. There should also be sufficient materials to precede the teaching learning process or education. The number of students also affects quality. [interview 403: ME].

Finally, students pointed out that teachers should be qualified and highly skilled. In general, the effect of teaching without pedagogical training at SPHMMC has a great influence on the students' acquired knowledge and on the teachers' capacity to achieve the learning outcome, which is a good-quality education. 


\section{Discussion}

Pedagogy involves the study of how to deliver lessons to students in the best way and enable a high quality of learning through this process. In pedagogy, teachers deal with the theory and practice of achievement in their classes. However, in our study most of the teaching processes took place without pedagogical training, with individual teachers using their own personal teaching methods. Except for two respondents, who had received a month and a year of pedagogical training, most of the respondents had received an average of only 2-7 days of training in pedagogy. This finding was similar to the results of a study conducted on the teaching and pedagogical training of university teaching staff in Slovenia, which revealed that only one-third of respondents had participated in higher education pedagogical training. ${ }^{5}$ The similarity of these findings may be due to the same status or level of quality of the teaching-learning process in the two studies.

In this study, the evaluation system showed that some teachers focused on only a few learning units and others prepared exams from content that the students had not learnt, and which did not have a table of specifications. This has a negative effect on the students' evaluation outcomes. This finding is in line with a study conducted in Malaysia, on the validity of teacher-made assessment, which revealed that the majority of teachers had never attended courses concerning tables of specifications and were unable to build a comprehensive table of specifications for the subjects that they taught. This indicates that teachers lack basic knowledge in designing a standard table of specifications and they lack awareness of the importance of such tables. ${ }^{19}$

This study revealed that there was a shortage of trained teachers. The college simply recruited teachers without checking their pedagogical training background. This is consistent with a study conducted in Kenyan universities, where there was a shortage of lecturers, which reduced the effectiveness of those lecturers in providing quality education. Thus, to cope with a shortage of lecturers and to minimize staff workload, there may be a tendency to employ incompetent staff for teaching. ${ }^{\text {? }}$

Most of the teachers in this study used one-way lecture methods, especially for the first and second years. In contrast, a study from Jamaica revealed that most teachers used interactive teaching approaches (discussion and cooperative learning strategies) to improve students' understanding and participation. ${ }^{20}$ This may be due to the different structure of the education system.

In SPHMMC, most of the teachers' assessment was focused on cognitive aspects of learning. Although the design of evaluation tools promoted the preparation of questions from easy to difficult levels, the teachers mostly used MCQs and matching questions. If students score good grades, they do not complain; however, from the students' perspective, teachers do not apply a proper evaluation system. They do not control students' work and, as a result, their evaluation is not fair. However, the literature supports the idea that students' motivation to learn in college depends on their academic expectations regarding their teachers' approach, knowledge, self-evaluation in study achievements, and the grading system of the institution. ${ }^{21}$ The gap here may be due to the teachers' lack of pedagogical training.

In a study conducted in Africa, in ten countries including Ethiopia, it was reported that the teaching-learning process is not interesting, as a result of various conditions. Class presentations are boring, the lecturers' teaching approach is not student centered, and some lecturers even avoid students' questions during lectures. Students have also mentioned that some instructors have difficulty in conducting classes and they simply read their notes or show slides to students during lectures. ${ }^{22}$

This result is in line with our study findings and may be due to a lack of pedagogical training practice.

In our study, students stated that the quality of the teaching method in the college had a great effect on their performance. Most of the students were not satisfied with the current teaching methodology. Similarly, a study conducted in Jordan revealed that students' quality of life was affected by their level of satisfaction with the faculty, teaching methods, and academic reputation..$^{23}$ This may be because of the similar status of the quality of teaching methods in these studies.

The teachers' as well as the students' perceptions in this study were that pedagogical training is very important to the college. They believed that training could change the way in which courses were delivered for the better, as quality education is expressed through teachers' readiness and students' active participation. Another study also stated that high levels of knowledge of the subject matter are positively associated with effective teaching practices, such as the use of hands-on and laboratory activities, decreased dependence on texts, and higher levels of comfort in facilitating student discussions. ${ }^{21}$

\section{Strengths}

The use of qualitative methodology in this study allowed each participant to provide an in-depth perspective, which would have been impossible with quantitative methodology. In addition, data saturation was achieved through the interview process, which indicates that an adequate number of 
interviews was conducted. Teachers' and students' perspectives were well addressed.

\section{Limitations}

This study had some limitations. Lecturers and students from all departments were not equally represented in the data, as we selected them purposefully. This research may not be generalizable as this was a qualitative study.

\section{Conclusion}

Only a few teachers in this study have a pedagogical background. Most of them use traditional lecture methods without providing the course objectives or syllabus to the students. They use bulky course contents without a proper lesson plan. Concerning the assessment method, most of the teachers focus on cognitive domains and do not use tables of specifications, which affects the students' evaluation. In addition, there are no evaluation mechanisms for teachers' performance. The effect of teaching without pedagogical training at SPHMMC has a great influence on the students' general knowledge and on the teachers' capacity to achieve quality education.

Quality education is expected through teachers' pedagogical readiness, students' active participation, and the provision of sufficient materials. Therefore, the college should give due attention to providing pedagogical training to all teaching staff. There should be a proper delivery system and evaluation mechanism. Teachers should upgrade themselves and be competent to deliver quality education to the students. Students should also practice giving constructive feedback to improve the teaching-learning process. As a result, effective and quality outcomes can be achieved. Further research in this field is vital to improve the quality of teaching in higher medical colleges and universities.

\section{Acknowledgments}

The authors would like to thank St. Paul's Hospital Millennium Medical College for funding the data collection process. Our gratitude goes to the supervisors, data collectors, and respondents who participated in the study. We would like also to thank Mr Tekalign Zewdie and Dr Rania Ibrahim for the English language editing of the manuscript.

\section{Author contributions}

The corresponding author took the lead role in writing the proposal, submission, and follow-up for ethical review. All authors contributed toward to the study design, data collection, data analysis, drafting and critically revising the paper, gave final approval of the version to be published, and agree to be accountable for all aspects of the work.

\section{Disclosure}

The authors report no conflicts of interest in this work.

\section{References}

1. Pacetti E. Improving the quality of education in Palestine through e-learning and ICT: the bottom-up approach for a sustainable pedagogy. In: Proceedings of the Conference on Knowledge Construction in E-learning Context. Available from: https://www.researchgate.net/ publication/221034322_Improving_the_Quality_of_Education_in_Palestine_through_e-Learning_and_ICT_The_Bottom-up_Approach_ for_a_Sustainable_Pedagogy. Accessed November 21, 2018.

2. Hénard F, Roseveare D. Fostering Quality Teaching in Higher Education: Policies and Practices. An Institutional Management in Higher Education (IMHE) Guide for Higher Education Institutions. Paris: OECD; 2012.

3. Berk RA. Survey of 12 strategies to measure teaching effectiveness. Int J Teaching Learn Higher Educ. 2005;17:48-62.

4. Hosoya S, Talib MT. Pre-service teachers' intercultural competence: Japan and Finland. In: Mattheou D, editor. Changing Educational Landscape: Educational Practice, Schooling Systems and Higher Education - A Comparative Perspective. New York: Springer; 2010;241-260.

5. Aškerc K, Kočar S. Teaching and the Pedagogical Training of University Teaching Staff - Practice and Opinions under Slovenian Higher Education Legislation. Educ Inquiry. 2005;6(2):Article: 25591.

6. Akullu Ezati B, Opolot-Okurut C, Namubiru Ssentamu P. Addressing Pedagogical Training Needs of Teaching Staff: Lessons from Makerere University Short Professional Development Programs 2006-2010. Am J Educ Res. 2014;2(12):1190-1198.

7. Gudo CO, Olel MA, Oanda IO. University Expansion in Kenya and Issues of Quality Education: Challenges and Opportunities. Int J Business Soc Sci. 2011;2(20):203-214.

8. Cavner D, Fox J. 21 st Century Teaching and Learning in Ethiopia: Challenges and Hindrances, Conference Paper. Int J Pedagogy Curriculum. 2014;22(2):2-9.

9. Abebe W, Woldehanna T. Teacher Training and Development in Ethiopia: Improving Education Quality by Developing Teacher Skills, Attitudes and Work Conditions. Oxford: Young Lives; 2013.

10. World Health Organization, Johns Hopkins Program for International Education in Gynecology and Obstetrics. Effective Teaching: A Guide for Educating Healthcare Providers. Baltimore, MD: JHPIEGO/Geneva: WHO; 2008.

11. World Health Organization. Transforming and scaling up health professionals' education and training. WHO Education Guidelines. Geneva: WHO; 2013.

12. Pleschová G, Simon E, Quinlan KM, Murphy J, Roxa T, Szabó M; Standing Committee for the Social Sciences (SCSS). The professionalisation of academics as teachers in higher education. European Science Foundation; 2012. Available from: http://archives.esf.org/fileadmin/ Public_documents/Publications/professionalisation_academics.pdf. Accessed December 10, 2016.

13. Shirani Bidabadi N, Nasr Isfahani A, Rouhollahi A, Khalili R. Effective teaching methods in higher education: requirements and barriers. $J A d v$ Med Educ Prof. 2016;4(4):170-178.

14. Dooge J. Engineering Training and Education. Dublin: Collins Press; 2007.

15. Khodaparasthaghi A. New perspectives in engineering education: the promotion of traditional models to innovative solutions. J Engg Educ. 2005;7(28):11-22. Persian.

16. Fisher R, Swindells D. The development priorities of Ethiopian higher education teachers. J In-Service Educ. 1998;24(2):307-315.

17. Chin C, Osborne J. Students' questions: a potential resource for teaching and learning science. Stud Sci Educ. 2008;44(1):1-39. 
18. Dole S, Bloom L, Kowalske. K. Transforming Pedagogy: Changing Perspectives from Teacher-Centered to Learner-Centered. Interdisciplinary J Probl Based Learn. 2016;10(1):2-9.

19. Mee Ing L, Borhandden Musah M, Tahir L, Kamil NM, Al-Hudawi SH. Validity of Teacher-Made Assessment: A Table of Specification Approach. Asian Soc Sci. 2015;5:1911-2025.

20. Riley CK, Myers BD. Incorporating Interactive Teaching Approaches in the Tertiary Science Classroom; Benefits, Challenges and Deterrents to Use in a Jamaican University. Sci J Educ. 2014;2(5): $146-151$.
21. Weimer MT. 10 Benefits of Getting Students to Participate in Classroom Discussions. Faculty Focus; 2011. Available from: https://www.facultyfocus.com/articles/teaching-and-learning/10-benefits-of-getting-studentsto-participate-in-classroom-discussions/. Accessed December 12, 2016.

22. Olatunji MO. Ensuring and promoting the pedagogical competence of university lecturers in Africa. J Educ Instruc Stud World. 2013;3(3):Article 12.

23. Saif NI. The Effect of Service Quality on Student Satisfaction: A Field Study for Health Services Administration Students. Int J Human Soc Sci. 2014;4(8):174.

\section{Publish your work in this journal}

Advances in Medical Education and Practice is an international, peerreviewed, open access journal that aims to present and publish research on Medical Education covering medical, dental, nursing and allied health care professional education. The journal covers undergraduate education, postgraduate training and continuing medical education including emerging trends and innovative models linking education, research, and health care services. The manuscript management system is completely online and includes a very quick and fair peer-review system. Visit http://www.dovepress.com/testimonials.php to read real quotes from published authors.

Submit your manuscript here: http://www.dovepress.com/advances-in-medical-education-and-practice-journal 